\title{
Судовые энергетические установки
}

DOI: http://www.dx.doi.org/10.24866/2227-6858/2019-4-10

УДК 629.5.03

М.Н. Покусаев, М.Ф. Руденко, А.А. Хмельницкая, К.Е. Хмельницкий

ПОКУСАЕВ МИХАИЛ НИКОЛАЕВИЧ - д.Т.н., профессор, заведующий кафедрой, AuthorID: 499461, SPIN: 9543-2110, e-mail: evt@astu.org

ХМЕЛЬНИЦКАЯ АНАСТАСИЯ АЛЕКСАНДРОВНА - ассистент кафедры, e-mail: khmelnitskayaaa@mail.ru

ХМЕЛЬНИЦКИЙ КОНСТАНТИН ЕВГЕНЬЕВИЧ - аспирант, e-mail: chuchera80@mail.ru

Кафедра «Эксплуатация водного транспорта»

РУДЕНКО МИХАИЛ ФЕДОРОВИЧ - д.Т.Н., профессор, заведующий кафедрой

«Безопасность жизнедеятельности и гидромеханика»,

AuthorID: 138470, SPIN: 7914-2130, e-mail: rudenko@astu.org

Астраханский государственный технический университет

Татищева ул., 16B, Астрахань, Россия, 414056

\section{Оценка экологической безопасности двухтактных подвесных лодочных моторов маломерных судов}

Аннотация: Проводится оценка экологической безопасности двухтактных подвесных лодочных моторов с учетом вредных выбросов в атмосферу и гидросферу, а также вибрации и шума. Для оценки критерия экологической безопасности использована методика интегральных коэффициентов. Расчеты произведены по результатам авторских экспериментов с мотором марки «Ветерок-8М» в малом опытовом бассейне испытательного центра Marine Technology Service Астраханского государственного технического университета и по данным нормативно-технической документации. Вредные выбросы нефтепродуктов в гидросферу от двухтактных подвесных лодочных моторов ранее не учитывались в подобных расчетах и в настоящее время не регламентируются в нормативной документации. Полученные авторами результаты могут применяться для практической оценки вредного влияния двухтактных подвесных лодочных моторов на окружающую среду. Авторы рекомендуют регламентировать вредные выбросы не только в атмосферу, но и в гидросферу и ввести соответствующие изменения в существующую нормативную документацию.

Ключевые слова: судовые энергетические установки, подвесные лодочные моторы, экологическая безопасность судов, влияние сбросов нефтепродуктов.

\section{Введение}

Ужесточение экологических требований к энергетическим установкам различного назначения привело к необходимости оценки ущерба для окружающей среды от даже относительно небольших по мощности двигателей внутреннего сгорания, включая подвесные лодочные моторы (ПЛМ), число которых весьма велико: например, только в Астраханской области на 2016 г. их зарегистрировано в Государственной инспекции по маломерным судам (ГИМС) МЧС Российской Федерации 18 982. Для данных типов двигателей регламентиру-

() Покусаев М.Н., Руденко М.Ф., Хмельницкая А.А., Хмельницкий К.Е., 2019 университет.

О статье: поступила: 04.11.2019; финансирование: бюджет - Астраханский государственный технический 
ются следующие экологические характеристики: вредные выбросы в атмосферу, шум, вибрации. Подавляющее большинство современных ПЛМ осуществляет основную часть выбросов отработавших газов через дейдвуд в гидросферу. Кроме того, двухтактные ПЛМ из-за особенностей цикла и конструкции производят сбросы в воду части топливной смеси, что приводит к высокому локальному загрязнению гидросферы в области выхлопа. Однако двухтактные ПЛМ широко используются на маломерных судах, так как их достоинства - простота конструкции и эксплуатации, относительно низкая цена и высокая надежность. Четырехтактные ПЛМ имеют более сложную конструкцию и высокую цену, но они более экологичны по сравнению с двухтактными ПЛМ.

Нормативная база, определяющая экологические требования для ПЛМ, основана на ряде документов $[1,2,3,7]$. ГОСТ 28556-16 «Моторы лодочные подвесные. Общие требования безопасности» [1] ввел обновленные требования по выбросам оксидов углерода (CO), углеводородов $(\mathrm{HC})$, оксидов азота $\left(\mathrm{NO}_{\mathrm{x}}\right)$, твердых частиц, а также по уровню шума и вибрации. Однако, например, для ПЛМ, поставленных на производство до 01.01.2017 года, уровень шума должен соответствовать требованиям ГОСТ 17.2.4.04-82 «Охрана природы. Атмосфера. Нормирование внешних шумовых характеристик судов внутреннего и прибрежного плавания» [2], установленных в 1982 году. При практических испытаниях ПЛМ на экологические характеристики эти характеристики должны соответствовать документу ГИМС «Программа и методика измерения объемных долей оксида углерода $(\mathrm{CO})$ и суммы углеводородов $(\mathrm{CH})$ в отработавших газах моторов лодочных при проведении технического освидетельствования. 770020000 ПМ 28. М» [3]. В нормативной документации, регламентирующей требования по предельному содержанию нефтепродуктов в рыбохозяйственных водоемах, отсутствуют требования по содержанию выбросов нефтепродуктов от ПЛМ в гидросферу. Количественное определение выбросов нефтепродуктов от ПЛМ сложно, это связано с большим объемом воды в водоемах, размытием выбросов гребным винтом, а также сложностью их измерения непосредственно в месте выхлопа. Однако результаты проведенных авторских экспериментов [8] и исследований отечественных и зарубежных ученых $[4,9-11]$ свидетельствуют о том, что вредные выбросы в воду от двухтактных ПЛМ могут образовывать весьма существенные загрязнения гидросферы, которые влияют на качество воды, флору, фауну и наносят ущерб окружающей среде. Следовательно, необходим учет подобных загрязнений при оценке экологической безопасности эксплуатации двухтактных ПЛМ.

Цель настоящей статьи - оценка экологической безопасности двухтактных подвесных лодочных моторов с учетом вредных выбросов в атмосферу, гидросферу, а также вибрации и шума на основе авторских экспериментов.

\section{Оценка экологической безопасности двухтактного ПЛМ «Ветерок-8М»}

Оценка экологической безопасности различных технологий или инженерных систем может быть произведена при помощи методики интегральных коэффициентов, разработанной профессором И.И. Мазуром и дополненной профессором М.Ф. Руденко [5]. В общем виде критерий оценки экологической безопасности рассчитывается по формуле

$$
J_{k}[\varepsilon]=\sum W\left(\varepsilon_{\text {атм }}\right) \cdot \sum W\left(\varepsilon_{\text {вода }}\right) \cdot \sum W\left(\varepsilon_{\text {почва }}\right) \cdot \sum W\left(\varepsilon_{\text {метеор }}\right) \cdot W(S) \cdot W(\mathrm{\Psi}),
$$

где $\sum W\left(\varepsilon_{\text {атм }}\right) \cdot \sum W\left(\varepsilon_{\text {вода }}\right) \cdot \sum W\left(\varepsilon_{\text {почва }}\right)-$ критерии экологическической безопасности атмосферы, гидросферы и почвы, которые равны суммам отношений концентраций вредных веществ к предельным допустимым концентрациям (ПДК) этих веществ в атмосфере, воде и почве, $г / \mathrm{M}^{3}$;

$\sum W\left(\varepsilon_{\text {метеор }}\right)$ - влияние метеорологических условий (ветра, осадков, температуры);

$\mathrm{W}(\mathrm{S})$ - критерий отчуждения земли;

$\mathrm{W}(Ч)$ - критерий безопасности и трудоемкости. 

формуле

В случае с ПЛМ критерий оценки экологической безопасности будет определяться по

$$
J_{k}[\varepsilon]=\sum W\left(\varepsilon_{\text {атм }}\right) \cdot \sum W\left(\varepsilon_{\text {вода }}\right) \cdot \sum W\left(\varepsilon_{\text {шум }}\right) \cdot \sum W\left(\varepsilon_{\text {вибр }}\right),
$$

где отдельные критерии будут вычисляться по формулам:

$$
\sum W\left(\varepsilon_{\text {атм }}\right)=\frac{C_{C O}}{\Pi д \kappa_{C O}}+\frac{C_{C H}}{\Pi д \kappa_{C H}},
$$

где $\mathrm{C}_{\mathrm{CO}}$ - средние выбросы СО, об.\% в газах ПЛМ;

ПДК

$\mathrm{C}_{\mathrm{CH}}-$ средние выбросы $\mathrm{CH}, \mathrm{ppm}$ в газах ПЛМ;

ПДК $\mathrm{CH}_{-}$предельное допустимое содержание $\mathrm{CH}, \mathrm{ppm}$ в газах ПЛМ.

$\sum W\left(\varepsilon_{\text {вода }}\right)=\frac{\mathrm{C}_{\text {нефт }}}{\text { ПдК } \kappa_{\text {нефт }}}$,

где $\mathrm{C}_{\text {нефт }}$ - количество вредных выбросов нефтепродуктов в воду от ПЛМ, мг/дм ${ }^{3}$;

ПДК нефт - предельное допустимое содержание нефтепродуктов в воде, мг/дм³

$\sum W\left(\varepsilon_{\text {шум }}\right)=\frac{\mathrm{C}_{\text {шум }}}{\text { ПдК шум }}$

где $\mathrm{C}_{\text {шум }}$ - уровень шума от ПЛМ, дБА;

ПДК шум - предельный допустимый уровень шума от ПЛМ, дБА.

$\sum W\left(\varepsilon_{\text {вибр }}\right)=\frac{\mathrm{C}_{\text {вибр }}}{\text { ПдК } \kappa_{\text {вибр }}}$,

где $\mathrm{C}_{\text {вибр }}$ - уровень вибрации ПЛМ;

ПДК вибр - предельный допустимый уровень вибрации ПЛМ.

Положительная оценка экологической безопасности присваивается технической системе или механизму в случае $J_{k}[\varepsilon]<1$.

\section{Результаты исследований}

Вредные выбросы СО (об.\%) и СН (ppm) определены при испытаниях ПЛМ «Ветерок$8 \mathrm{M»} \mathrm{в} \mathrm{малом} \mathrm{опытовом} \mathrm{бассейне} \mathrm{испытательного} \mathrm{центра} \mathrm{Marine} \mathrm{Technology} \mathrm{Service} \mathrm{(см.} \mathrm{ри-}$ сунок) при помощи газоанализатора «Инфракар-А-02», поверенного и сертифицированного средства измерения. Объем воды в малом опытовом бассейне составляет 550 л $\left(0,55 \mathrm{~m}^{3}\right)$.

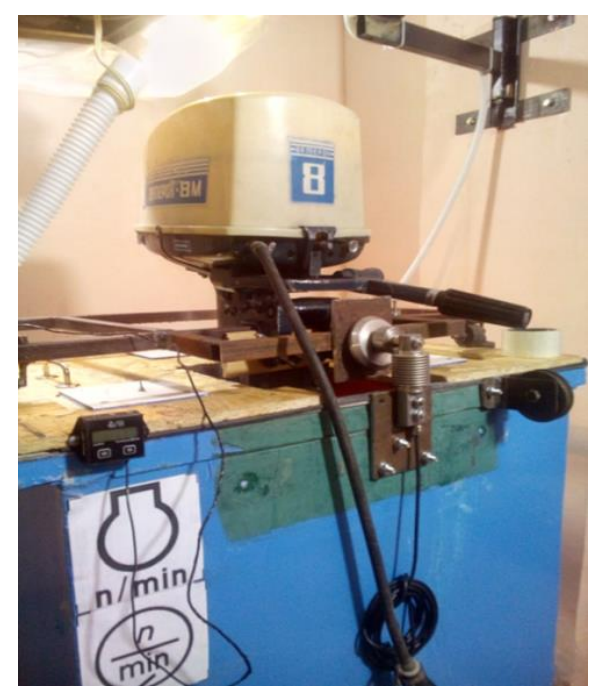

\section{Испытания ПЛМ «Ветерок-8М» в малом опытовом бассейне испытательного центра Marine Technology Service.}

Выбросы нефтепродуктов от ПЛМ определялись по результатам анализа воды, проведенного в аккредитованной лаборатории Государственного центра агрохимической службы 
«Астраханский» при эксплуатации ПЛМ «Ветерок-8М»в малом опытовом бассейне в течении 10 мин на режиме холостого хода [8]. Данные для расчета индексов по вибрации и шуму взяты из результатов дополнительных экспериментов, проведенных авторами с ПЛМ «Ветерок-8М». Измерения шума и вибрации производились при помощи виброметра-шумомера «Экофизика-110B», виброметра AR63A и шумомера Uniontest SM135.Оценка вибрации на рукоятке румпеля ПЛМ потребовала дополнительного анализа. Определяющим параметром вибрации, согласно ГОСТ 28556-16 «Моторы лодочные подвесные. Общие требования безопасности» [1], является виброускорение на рукоятке румпеля, при частоте вращения ПЛМ, равной половине максимальной частоты вращения. Для ПЛМ «Ветерок-8М» максимальная частота вращения составляет 4800-5000 об/мин, т.е. частота, на которой следует оценивать виброускорение, составляет 2400-2500 об/мин. Определенное на испытаниях значениевиброускорения составляет $15,7 \mathrm{mM} / \mathrm{c}^{2}$. Согласно ГОСТ 28556-16 «Моторы лодочные подвесные. Общие требования безопасности» [1], предельное значение указывается изготовителем ПЛМ в инструкции при эксплуатации, но для «Ветерок-8М» такой параметр не был указан. Предельные значения виброускорения в помещениях для речных судов (категория помещения 4) в соответствии с СH 1103-73 «Санитарные нормы вибрации на морских, речных и озерных судах» [6] не должны превышать по относительному уровню 63 дБ для низкочастотной вибрации с частотой 63 Гц. Согласно переводной таблице № 5 из [6], 1,57·10 $0^{-2} \mathrm{M} / \mathrm{c}^{2}$ соответствует относительному уровню 34 дБ.

Измеренный авторами уровень шума для ПЛМ «Ветерок-8М» составил 67,4 дБА, а допустимый уровень шума, согласно ГОСТ 17.2.4.04-82 «Охрана природы. Атмосфера. Нормирование внешних шумовых характеристик судов внутреннего и прибрежного плавания» [2], не должен превышать 75 дБА, что позволяет говорить о допустимой величине шума рассматриваемого ПЛМ.

Для удобства расчета критерия оценки экологической безопасности ПЛМ «Ветерок8М» произведем его в табличном виде (см. таблицу).

Критерий оценки экологической безопасности для ПЛМ «Ветерок-8М»

\begin{tabular}{|c|c|c|c|c|c|c|c|}
\hline Параметр & Значение & Параметр & Значение & Параметр & Значение & Параметр & Значение \\
\hline $\mathrm{C}_{\mathrm{CO}}$, об.\% & 3,50 & $\mathrm{C}_{\text {нефт }}, \mathrm{M \Gamma} /$ дм $^{3}$ & 3,73 & $\mathrm{C}_{\text {шум }}$, дБА & 67,4 & $\mathrm{C}_{\text {вибр }}$, дБ & 34 \\
\hline $\begin{array}{c}\text { ПДК } \\
\text { об.\% }\end{array}$ & 4,80 & $\begin{array}{c}\text { ПДК } \\
\text { мгефт }^{3} \text { дм }^{3} \\
\end{array}$ & 0,05 & $\begin{array}{c}\text { ПДК шум, } \\
\text { дБА }\end{array}$ & 75 & ПДК вибр, дБ & 63 \\
\hline $\mathrm{C}_{\mathrm{CH}}, \mathrm{ppm}$ & 5588 & \multirow{3}{*}{$\sum W\left(\varepsilon_{\text {вода }}\right)$} & \multirow{3}{*}{74,6} & \multirow{3}{*}{$\sum W\left(\varepsilon_{\text {шум }}\right)$} & \multirow{3}{*}{0,9} & \multirow{3}{*}{$\sum W\left(\varepsilon_{\text {вибр }}\right)$} & \multirow{3}{*}{0,54} \\
\hline $\begin{array}{c}\text { ПДК } \\
\text { ppm }\end{array}$ & 6000 & & & & & & \\
\hline$\sum W\left(\varepsilon_{\text {атм }}\right)$ & 1,66 & & & & & & \\
\hline
\end{tabular}

Таким образом, критерий оценки экологической безопасности для ПЛМ «Ветерок$8 \mathrm{M»} \mathrm{рассчитывается} \mathrm{по} \mathrm{формуле}$

$$
J_{k}[\varepsilon]=1,66 \cdot 74,6 \cdot 0,9 \cdot 0,54=60,08 .
$$

Поскольку для положительной экологической оценки механизма или системы необходимо, чтобы выполнялось условие $J_{k}[\varepsilon]<1$, очевидно, что ПЛМ «Ветерок-8М» оказывает вредное воздействие на окружающую среду, при этом существенная доля вредного воздействия приходится именно на выбросы нефтепродуктов в воду. Если эти выбросы не учитывать, то критерий оценки экологической безопасности для ПЛМ «Ветерок-8М» будет рассчитываться по формуле

$$
J_{k}[\varepsilon]=1,66 \cdot 0,9 \cdot 0,54=0,81 .
$$

Критерий экологической безопасности без учета вредных выбросов нефтепродуктов в воду меньше единицы, что дает, на наш, взгляд, ложное представление об экологической 
безопасности ПЛМ для окружающей среды. Следует учесть, что выбросы в воду со временем постепенно уменьшаются за счет размытия водой, испарения, осаждения, поэтому в данном случае рассматриваются концентрированные локальные выбросы.

Для учета выбросов нефтепродуктов в водоем введем поправочный коэффициент с учетом реального объема воды. Объем воды, в котором находятся сбросы нефтепродуктов от ПЛМ «Ветерок», можно рассчитать исходя из предположения, что при работе ПЛМ на холостом ходу выбросы будут удаляться от лодки со скоростью течения (выбросы легче лодки, поэтому их движение относительно нее будет присутствовать даже с учетом движения лодки по течению), которое в реке Волга в районе Астрахани составляет 1 м/с. С минимальной допустимой глубиной для эксплуатации ПЛМ водоема 0,8 м и времени эксплуатации на холостом ходу 10 мин длина размыва выбросов от ПЛМ составит 600 м, а при ширине следа выбросов от ПЛМ, равной 0,8 м (ширина малого опытового бассейна, в котором проходили лабораторные испытания), соответственно, объем загрязненной воды составит $384 \mathrm{~m}^{3}$. Таким образом, поправочный коэффициент реального объема воды в водоеме составит: 0,55/384 = 0,0014 .

При введении такого поправочного коэффициента критерий экологической оценки ПЛМ может быть рассчитан по формуле

$$
\mathrm{J}_{\mathrm{k}}[\varepsilon]=1,66 \cdot 74,6 \cdot 0,9 \cdot 0,54 \cdot 0,0014=0,08 .
$$

Как свидетельствует проведенный расчет, даже при учете течения реки и режиме холостого хода ПЛМ размытие вредных выбросов довольно сильно снижает вредное влияние ПЛМ на окружающую среду. Тем не менее при снижении скорости течения, что наблюдается на маловодных участках рек и в озерах, заводях и т.д., вредное воздействие на окружающую среду со стороны ПЛМ усиливается - вплоть до максимального при нулевой скорости течения. При скоростном движении лодки объем воды существенно увеличивается, снижая общие выбросы нефтепродуктов от ПЛМ до минимума.

\section{Выводы}

По результатам проведенных исследований мы можем сделать следующие выводы.

1. Наличие большого объема воды в водоеме и скоростное движение моторной лодки снижает вредное влияние от ПЛМ, однако на участках рек и водоемов с низким течением загрязнение гидросферы может существенно усилиться.

2. Оценка экологической безопасности ПЛМ с учетом выбросов в гидросферу необходима, поскольку концентрированные выбросы нефтепродуктов имеют высокие значения в локальных объемах воды.

3. Необходимы разработка нормативной документации и установка предельно допустимых концентраций по сбросам нефтепродуктов в гидросферу от ПЛМ.

4. В дальнейшем, мы полагаем, необходимы исследования для оценки загрязнений воды от ПЛМ с учетом подъема на поверхность водоема и испарения легких фракций нефтепродуктов.

\section{СПИСОК ЛИТЕРАТУРЫ}

1. ГОСТ 28556-16. Моторы лодочные подвесные. Общие требования безопасности. М.: Стандартинформ, $2016.11 \mathrm{c}$.

2. ГОСТ 17.2.4.04-82. Охрана природы. Атмосфера. Нормирование внешних шумовых характеристик судов внутреннего и прибрежного плавания. 1982. 5 с.

3. Моторы лодочные. Программа и методика измерения объемных долей оксида углерода (СО) и суммы углеводородов $(\mathrm{CH})$ в отработавших газах моторов лодочных при проведении технического освидетельствования. 770020000 ПМ 28. М., 2001. 8 с. 
4. Плотников В.К. О количественной оценке загрязнения воды маломерными судами // Катера и яхты. 1981. № 91. URL: http://www.barque.ru/horizon/1981/contamination_of_water_small_boats (дата обращения: 15.10.2019).

5. Руденко М.Ф., Шипулина Ю.В., Бобракова С.Д. Оценка экологической безопасности при внедрении гелиоэнергетических систем для производства теплоты // Геология, география и глобальная энергия. 2014. № 3(54). С. 159-161.

6. СН 1103-73. Санитарные нормы вибрации на морских, речных и озерных судах. 1973.8 с.

7. Технический регламент таможенного союза ТР ТС 026/2012. О безопасности маломерных судов. 2012.38 с.

8. Хмельницкая А.А., Покусаев М.Н., Сибряев К.О., Ковалев О.П., Булгаков В.П. Экспериментальная оценка загрязнения гидросферы нефтепродуктами подвесным лодочным мотором «Ветерок-8М»// Вестник Волжской государственной академии водного транспорта, 2019. № 58. C. 54-60.

9. Anastasios Karkanis, Charalampos Arapatsakos, Christina Anastasiadou. Experimental measurement of load and exhaust gas emissions on an outboard engine. Advances in Environmental Sciences, Development and Chemistry. 2014, 221-227 p.

URL: http://inase.org/library/2014/santorini/bypaper/ENVIR/ENVIR-00.pdf - 15.10.2019.

10. Charles Kelly. Analysis of the underwater emissions from outboard engine S.Queensland Univ. Technology, Brisbane, Australia. 2004. 207 p. URL: https://www.eprints.qut.edu.au/16448/ [Deposited On: 03 Dec 2008 04:03] - 15.10.2019.

11. Potential impacts of emissions from outboard motors on the aquatic environment: a literature review. NIWAClient Report: HAM2007-026. March 2007, 33 p.

URL: http://inase.org/library/2014/santorini/bypaper/ENVIR/ENVIR-00.pdf - 15.10.2019.

FEFU: SCHOOL of ENGINEERING BULLETIN. 2019. N 4/41

Ship Power Plants www.dvfu.ru/en/vestnikis

DOI: http://www.dx.doi.org/10.24866/2227-6858/2019-4-10

Pokusaev M., Rudenko M., Khmelnitskaya A., Khmelnitsky K.

MIKHAIL POKUSAEV, Doctor of Engineering Sciences, Professor, Head of the Department, AuthorID: 499461, SPIN: 9543-2110, e-mail: evt@astu.org ANASTASIA KHMELNITSKAYA, Assistant, e-mail: khmelnitskayaaa@mail.ru KONSTANTIN KHMELNITSKY, Postgraduate Student, e-mail: chuchera80@mail.ru Department Operation of Water Transport MIKHAIL RUDENKO, Doctor of Engineering Sciences, Professor, Head of the Department Life Safety and Hydromechanics, AuthorID: 138470, SPIN: 7914-2130, e-mail: rudenko@astu.org Astrakhan State Technical University 16B Tatishcheva St., Astrakhan, Russia, 414056

\section{Assessment of environmental safety of two-stroke outboard motors of small vessels}

Abstract: The article assesses the environmental safety of two-stroke outboard motors taking into account their harmful emissions into the atmosphere, hydrosphere, vibration and noise. To assess the criterion of environmental safety, the method of integral coefficients was used. The calculations were made on the basis of the results of the authors experiments with a two-stroke outboard motor of the brand Breeze-8M in the Marine Technology Service Test Center of the Astrakhan State Technical University and data taken from the regulatory and technical documentation. The novelty of the 
study is consideration of the harmful emissions of petroleum products into the hydrosphere, which were not previously taken into account in such calculations.

Keywords: ship power plants, outboard motors, environmental safety of small vessels.

\section{REFERENCES}

1. GOST 28556-16. Outboard boat motors. General safety requirements. Moscow, Standartinform, 2016, $11 \mathrm{p}$.

2. GOST 17.2.4.04-82. Nature protection. Atmosphere. Regulation of external noise characteristics of inland and coastal vessels. 1982, 5 p.

3. Boat motors. Program and method of measuring the volume fraction of carbon monoxide $(\mathrm{CO})$ and the amount of hydrocarbons $(\mathrm{CH})$ in the exhaust gases of boat engines during technical inspection. 770020000 PM 28. Moscow, 2001, 8 p.

4. Plotnikov V.K. On quantitative assessment of water pollution by small vessels. Boats and yachts. 1981;91. URL: http://www.barque.ru/horizon/1981/contamination_of_water_small_boats 15.10.2019.

5. Rudenko M.F., Shipulina Yu.V., Bobrakova S.D. Assessment of environmental safety in the implementation of solar energy systems for heat production. Geology, Geography and Global Energy. 2014;3:159-161.

6. CN 1103-73. Sanitary standards are applied on sea, river and lake vessels. 1973, 8 p.

7. Technical regulations of the customs Union TR CU 026/2012. On the safety of small vessels. 2012, 38 p.

8. Khmelnitskaya A.A., Pokusaev M.N., Sibryaev K.O., Kovalev O.P., Bulgakov V.P. Expert assessment of pollution of the hydrosphere with petroleum products by outboard boat motor Breeze- $8 M$. Bulletin of the Volga State Academy of Water Transport. 2019;58:54-60.

9. Anastasios Karkanis, Charalampos Arapatsakos, Christina Anastasiadou. Experimental measurement of load and exhaust gas emissions on an outboard engine. Advances in Environmental Sciences, Development and Chemistry. 2014; 221-227 p.

URL: http://inase.org/library/2014/santorini/bypaper/ENVIR/ENVIR-00.pdf - 15.10.2019.

10. Charles Kelly. Analysis of the underwater emissions from outboard engine S.Queensland Univ. Technology, Brisbane, Australia, 2004. 207 p. URL: https://www.eprints.qut.edu.au/16448/ [Deposited On: 03 Dec 2008 04:03] - 15.10.2019.

11. Potential impacts of emissions from outboard motors on the aquatic environment: a literature review. NIWAClient Report: HAM2007-026. March 2007, 33 p.

URL: https://envirolink.govt.nz/assets/Envirolink/24-wcrc4.pdf - 15.10.2019. 